\title{
Examining Twitter Discourse on Electronic Cigarette and Tobacco Consumption During National Cancer Prevention Month in 2018: Topic Modeling and Geospatial Analysis
}

Jiahui Lu ${ }^{1}$, PhD; Edmund W J Lee ${ }^{2}$, PhD

${ }^{1}$ School of New Media and Communication, Tianjin University, Tianjin, China
${ }^{2}$ Wee Kim Wee School of Communication and Information, Nanyang Technological University, Singapore, Singapore

Corresponding Author:

Jiahui $\mathrm{Lu}, \mathrm{PhD}$

School of New Media and Communication

Tianjin University

No 92 Weijin Road

Tianjin, 300072

China

Phone: 8618222418810

Email: 1ujiahui@tju.edu.cn

\section{Abstract}

Background: Examining public perception of tobacco products is critical for effective tobacco policy making and public education outreach. While the link between traditional tobacco products and lung cancer is well established, it is not known how the public perceives the association between electronic cigarettes (e-cigarettes) and lung cancer. In addition, it is unclear how members of the public interact with official messages during cancer campaigns on tobacco consumption and lung cancer.

Objective: In this study, we aimed to analyze e-cigarette and smoking tweets in the context of lung cancer during National Cancer Prevention Month in 2018 and examine how e-cigarette and traditional tobacco product discussions relate to implementation of tobacco control policies across different states in the United States.

Methods: We mined tweets that contained the term "lung cancer" on Twitter from February to March 2018. The data set contained 13,946 publicly available tweets that occurred during National Cancer Prevention Month (February 2018), and 10,153 tweets that occurred during March 2018. E-cigarette-related and smoking-related tweets were retrieved, using topic modeling and geospatial analysis.

Results: Debates on harmfulness (454/915, 49.7\%), personal experiences $(316 / 915,34.5 \%)$, and e-cigarette risks (145/915, $15.8 \%)$ were the major themes of e-cigarette tweets related to lung cancer. Policy discussions $(2251 / 3870,58.1 \%)$, smoking risks $(843 / 3870,21.8 \%)$, and personal experiences $(776 / 3870,20.1 \%)$ were the major themes of smoking tweets related to lung cancer. Geospatial analysis showed that discussion on e-cigarette risks was positively correlated with the number of state-level smoke-free policies enacted for e-cigarettes. In particular, the number of indoor and on campus smoke-free policies was related to the number of tweets on e-cigarette risks (smoke-free indoor, $r 49=0.33, P=.02$; smoke-free campus, $r 49=0.32, P=.02$ ). The total number of e-cigarette policies was also positively related to the number of tweets on e-cigarette risks $(r 49=0.32, P=.02)$. In contrast, the number of smoking policies was not significantly associated with any of the smoking themes in the lung cancer discourse $(P>.13)$.

Conclusions: Though people recognized the importance of traditional tobacco control policies in reducing lung cancer incidences, their views on e-cigarette risks were divided, and discussions on the importance of e-cigarette policy control were missing from public discourse. Findings suggest the need for health organizations to continuously engage the public in discussions on the potential health risks of e-cigarettes and raise awareness of the insidious lobbying efforts from the tobacco industry.

(J Med Internet Res 2021;23(12):e28042) doi: 10.2196/28042

\section{KEYWORDS}

electronic cigarette; smoking; lung cancer; Twitter; national cancer prevention month; policy; topic modeling; cessation; e-cigarette; cancer; social media; eHealth; cancer prevention; tweets; public health 


\section{Introduction}

\section{Background}

Tobacco control has been identified as a global public health priority by the World Health Organization [1]. Tobacco use is one of the leading causes of preventable deaths globally, and it is responsible for 7 million deaths worldwide [2]. In the United States, the Centers for Disease Control and Prevention (CDC) reported that tobacco use accounted for 1 in 5 deaths, leading to more than 480,000 deaths annually [3]. As such, for tobacco control, understanding public perception of tobacco products and their severe health risks, such as lung cancer, is essential to inform educational campaigns and tobacco control policies.

Particularly, health education campaigns and control policies should pay attention to tobacco consumption trends. In terms of traditional tobacco use, the CDC reported that smoking among adults had declined from $20.9 \%$ in 2005 to $13.7 \%$ in 2018 , and the proportion of smokers who reported quitting had increased [4]. But, the popularity of emerging tobacco products such as electronic cigarettes (e-cigarettes) has been rising steadily since 2010. E-cigarettes are electronic devices that are used to deliver nicotine and other chemicals to users through inhalable aerosols. The US Surgeon General declared that e-cigarette use was an epidemic among youth in 2018, given that $21 \%$ of high school seniors in the United States reported using e-cigarettes in the preceding 30 days in the same year [5]. In particular, Juul captured and dominated $73 \%$ of the e-cigarette market through its product promotion featuring youth culture and lifestyle on different social media platforms [6].

The overwhelming popularity of e-cigarettes may be due to conflicting messages in the public. Some argue that e-cigarettes could help with smoking cessation as they appear to pose fewer health risks than traditional cigarettes [7-9]. Meanwhile, others cautioned against e-cigarette consumption as they contain nicotine, a highly addictive drug, that can lead to the use of other tobacco products [10-12]. Even though there is no established connection between e-cigarette use and severe diseases such as lung cancer, there is evidence of lung injuries associated with its use [13-15]. Notably, the CDC declared an outbreak of lung injuries associated with e-cigarette use in 2019 [16].

\section{Related Work}

Survey studies have investigated the perceived associations of smoking traditional tobacco products and e-cigarettes with health diseases such as lung cancer. Smoking is recognized as a major risk factor for lung cancer by the public [17]. In contrast, the public may not view e-cigarettes as a likely cause of lung cancer $[18,19]$ but, instead, may view e-cigarettes as a safe alternative to combustible cigarettes [20,21]. There are very few studies that have compared public perceptions of both smoking and vaping in relation to severe health consequences using social media data. Currently, a growing body of social media studies $[22,23]$ on e-cigarettes and smoking show that e-cigarettes are often presented as a positive and healthier alternative to smoking, despite controversies surrounding their effectiveness in smoking cessation and the likelihood of initiating adolescents to consuming other tobacco products.
Nevertheless, there is limited evidence about the extent that the public perceives lung cancer to be a health consequence of both smoking and vaping [24-26]. Such comparisons are critical as they can highlight contextual, psychological, and behavioral factors specific to the reasons for which individuals consume different tobacco products. This knowledge is valuable as it can inform strategic messaging and educational programs to facilitate behavioral changes in reducing tobacco consumption [27].

Furthermore, to the best of our knowledge, none of the existing social media studies has investigated spatial patterns of tobacco conversations on social media in relation to implementation of health policies. For example, it has been found that the number of obesity-related policies in certain geographic regions were associated with an increase in obesity prevention discussions on Twitter within the same area [28]. This likely suggests that the number of health policies, or the policy environment in general, have a reciprocal relationship with consumers' health awareness. Putting this in the context of tobacco control, the number of state-level tobacco policies in the United States may be a reflection of the risk perception of tobacco products and e-cigarettes, and this heightened awareness of risk on a societal level may be impetus for policy makers to enact more laws to rein in tobacco consumption. Therefore, it is crucial to study how tobacco policies of the various states are associated with public perceptions and discussions of health effects of tobacco products on social media.

\section{Tobacco Discourse During US National Cancer Prevention Month}

While the majority of social media studies largely examine public discourse of e-cigarette and smoking in general, this study examined tobacco discourse in the context of US National Cancer Prevention Month, which is an annual campaign led by the American Institute for Cancer Research in the month of February that aims to foster cancer knowledge and promote cancer prevention practices [29]. Particularly, lung cancer, which is a deadly disease that is caused by tobacco consumption [30], is one of prominent cancer topics during the campaign. Past research has shown that month-long cancer campaigns, such as National Cancer Prevention Month, are the key to increasing awareness of cancer and its associated risk factors [31]. As such, National Cancer Prevention Month offer opportunities to examine e-cigarette and smoking discourse related to lung cancer.

Past research has shown that public discourse during cancer campaigns may be different from that during other months. Cancer campaigns raise public awareness by promoting cancer conversations about risk factors and preventions on Twitter [32]. Also, public discourse during cancer campaigns is often driven by health organizations, advocacy groups, and influential personalities such as celebrities [32,33]. The agenda of cancer campaigns typically involves disseminating cancer education messages, advocating prevention engagement, and sharing affective stories of survivors [33,34]. In addition to these messages, Twitter users could respond and selectively follow and express their own opinions on lung cancer. As such, public discourse during campaigns would likely reflect how the public 
interact with official messages on tobacco consumption and lung cancer. This knowledge can be important for public health officials in identifying gaps in health education.

\section{Objective}

First, we aimed to examine if National Cancer Prevention Month plays a role in promoting conversations on the link of e-cigarettes and smoking with lung cancer. Second, we aimed to examine and compare public discourse in the United States on smoking and e-cigarette in the context of lung cancer on Twitter during National Cancer Prevention Month. Third, we aimed to examine if there were spatial patterns of smoking and e-cigarette's themes in the United States during National Cancer Prevention Month. Fourth, we explored the relationship between e-cigarette and smoking discussions on Twitter during National Cancer Prevention Month with implementation of tobacco control policies. As such, we put forth 4 research questions: (1) Does national cancer prevention month promote e-cigarette and smoking conversation related to lung cancer? (2) What are the key themes in e-cigarette and smoking tweets within the broader context of lung cancer discussion during National Cancer Prevention Month? (3) Are there geospatial differences in how e-cigarette and smoking tweets were distributed across the United States during National Cancer Prevention Month? (4) What is the relationship between the number of tobacco control policies in states and themes of e-cigarette and smoking tweets?

\section{Methods}

\section{Data Collection}

Data were retrieved from an existing data set of US English-based lung cancer tweets that contained the term "lung cancer" purchased from Twitter. A list of 28 keywords, such as "e-cigarette," "vape," and "juul" [35,36], and another list of 21 keywords, such as "cigarette" and "smoking" [37], were developed and used to extract e-cigarette and smoking tweets from the data set, respectively (Table 1). Tweets that contained both sets of keywords were excluded from further analysis to obtain a proper comparison.

Table 1. Search keywords for data collection.

\begin{tabular}{ll}
\hline Topic & Keywords \\
\hline E-cigarette & $\begin{array}{l}\text { electronic cigarette; vap*; e-cig*; ecig*; e cig; e-pen; epen; e pen; e-juice; ejuice; e juice; e-liquid; eliquid; e liquid; esmoke; } \\
\text { e-smoke; e smoke; e-hookah; ehookah; e hookah; e-pipe; epipe; e pipe; atomizer; juul; njoy; v2 cig; joye510 }\end{array}$ \\
& $\begin{array}{l}\text { cig*; tobacco; waterpipe; water pipe; hooka; smok*; chew; nicotine; shisha; sheesha; bidi; beedi; kretek; narghile; argileh; } \\
\text { cheroot; snuff; snus; betel; gutkha; toombak }\end{array}$ \\
\hline
\end{tabular}

\section{Data Processing and Analysis}

R statistical software (The R Project) was used for textual analyses. Data were preprocessed and cleaned before advanced textual analysis. Texts were formatted to lower case. Different forms of phrases that had the same meaning were transformed into a common format to facilitate future text processing, such that "e cig," "e-cig," "ecig," and "electronic cigarette" were reformatted into "ecigarette." Common English stop words, such as "the" and "of," special characters, and punctuations were removed. The remaining texts were tokenized and lemmatized to further avoid inflected words. The word "lung cancer" was also removed from the analysis.

\section{Topic Modeling}

Topic modeling, using latent Dirichlet allocation, was employed to understand the differences between themes of e-cigarette and smoking in the context of lung cancer discourse. Latent Dirichlet allocation is a popular and widely used algorithm for topic modeling, by which documents are modeled as mixtures over topics and a topic is characterized as a distribution of words [38]. R software (topicmodels package [39]) was used.

The latent Dirichlet allocation algorithm requires a predefined number, $k$, of topics, which we determined with the perplexity and log-likelihood indices. Both indices have been conventionally used to evaluate the model $[38,40]$. A lower perplexity score and a higher log-likelihood score indicate better generalization performance. We trained topic models from $k=2$ to $k=20$. To maximize the diversity of discussion while at the same time minimize topic overlaps, we selected the $k$ model when the $k+1$ model did not improve [27,38]. After the topics were generated, we named each topic by examining keywords and posts that were representative of those topics. Topics deemed to have similar themes were combined to facilitate discussions.

To evaluate the prevalence of topics, we used methods described in [27] to determine the topic of each tweet. The output of topic modeling included estimates of the proportion of each topic present in each tweet. Based on this output, we assigned each tweet the topic that had the highest predicted proportion. For example, the tweet "February 7, 2018. The day everyone who juuls simultaneously got lung cancer" was estimated to be $1.1 \%$ similar to other tweets under the topic affective reasoning, 1.1\% similar to other tweets under the topic personal experiences, $95.6 \%$ similar to other tweets under the topic sarcasm, $1.1 \%$ similar to other tweets under the topic cognitive reasoning, and $1.1 \%$ similar to other tweets under the topic e-cigarette risk and was, therefore, classified under the topic sarcasm.

We compared the temporal distribution of e-cigarette and smoking tweets using chi-square analysis.

\section{Geospatial Analysis}

The geolocation of a tweet was determined by the self-reported location in the profile of the relevant Twitter user. We imported the location strings into the Google Maps geocoordinates application programming interface (API) to obtain the geocoordinates and the corresponding states in the United States. Then, we manually checked to ensure the state information is correct for each tweet. Tweets that did not have a user-reported location or whose reported location string did not return any 
results were excluded from the geospatial analysis. To further understand the spatial distribution of themes, ratio values were calculated for each state by dividing the number of tweets in each theme by the total number of tweets in each state. We plotted the ratio values by state to visualize the spatial distribution patterns.

To further understand how state policies might affect twitter discussions of e-cigarette and smoking, we compared the number of tweets with the number of state policies (existing, introduced, or recently enacted in the first quarter of 2018) related to e-cigarettes and smoking. State policies were obtained from the tobacco use data portal from the US CDC [41]. For e-cigarettes, the data included policies related to the sale of e-cigarettes to youth, retail licenses to sell e-cigarette, smoke-free indoor, smoke-free on campus, taxes on e-cigarette products, and preemption. For smoking, the data included all policies similar to those for e-cigarettes and additional policies on fire safety. We conducted bivariate correlation analysis (Pearson correlation) of the total number of tweets and the total number

Figure 1. Study flowchart. of state policies, as well as between the themes of tweets and types of tobacco control policies.

\section{Results}

\section{Temporal Distribution of E-cigarette and Smoking Tweets}

The data set had 13,946 publicly available tweets obtained during National Cancer Prevention Month (ie, February) and 10,153 tweets obtained during March in 2018 in the United States. The keyword queries returned 1061 e-cigarette tweets and 4019 smoking tweets during National Cancer Prevention Month, and 171 e-cigarette tweets and 1919 smoking tweets during March (Figure 1). Of these, 149 tweets during National Cancer Prevention Month and 95 tweets during March contained both sets of keywords and were removed. This yielded $6.56 \%$ $(915 / 13,946)$ e-cigarette tweets and $27.7 \%(3870 / 13,946)$ general smoking tweets made by 839 and 3501 unique users during National Cancer Prevention Month, and 0.75\% (76/10,153) e-cigarette tweets and $18.0 \%(1824 / 10,153)$ general smoking tweets made by 57 and 1643 unique users during March.

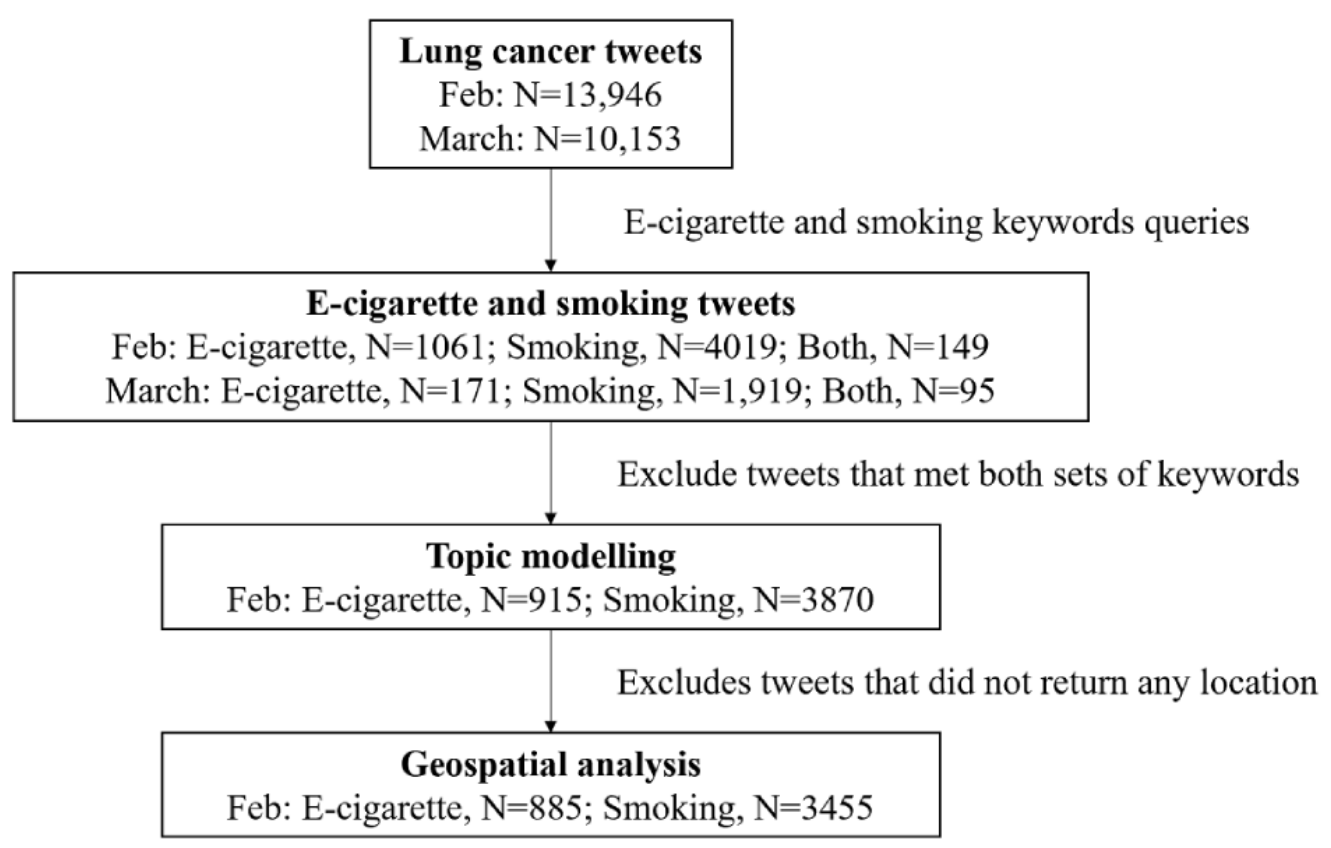

There was a significant difference between the temporal distributions for e-cigarette and smoking tweets $\left(\chi^{2}=256.85\right.$, $P<.001)$. This suggests that National Cancer Prevention Month did promote lung cancer discussion associated with e-cigarette and smoking.

\section{E-cigarette and Smoking Tweets Themes}

During National Cancer Prevention Month, 3 major e-cigarette themes-comprising 5 topics-emerged (Table 2). The topics affective reasoning, cognitive reasoning, and sarcasm were categorized under the overarching theme e-cigarette debate. First, Twitter users made the link between e-cigarettes and lung cancer based on emotional evaluation of their experiences or anecdotal stories they have heard. Second, there were those who discussed and cognitively processed e-cigarette information presented to them. For instance, one of the tweets highlighted that lung cancer could take years to develop and simply "juuling" for a short period may not be enough to develop lung cancer. Third, some of the Twitter users expressed sarcasm when discussing e-cigarettes, pushing back on the idea of "juuling" and lung cancer. These 3 topics accounted for half of all tweets $(454 / 915,49.7 \%)$. The second major theme was e-cigarette risks (145/915, 15.8\%), where many tweets discussed scientific evidence on the risks of e-cigarette on lung diseases. The third major theme was personal experiences, which constituted approximately one-third of the tweets (316/915, $34.5 \%$ ). Many tweets in this category encouraged others to stop vaping, with users citing stories they had heard about someone who contracted lung cancer by consuming e-cigarettes. 
Table 2. E-cigarette themes from tweets (based on latent Dirichlet allocation algorithm).

\begin{tabular}{|c|c|c|c|}
\hline Theme & Words & Examples & Tweets $(n=915), n(\%)$ \\
\hline E-cigarette debates & & & 454 (49.7) \\
\hline Affective reasoning & $\begin{array}{l}\text { Juul, hit, kid, people, rumor, cause, shit, } \\
\text { really, report, untrue }\end{array}$ & $\begin{array}{l}\text { Drop your juuls like deadass. Have heard of three } \\
\text { people my age who have been diagnosed with lung } \\
\text { cancer from juuls. Feel like we all saw this coming }\end{array}$ & $158(17.3)$ \\
\hline Cognitive reasoning & $\begin{array}{l}\text { Juul, year, cause, cancer, develop, know, } \\
\text { take, use, lung, say }\end{array}$ & $\begin{array}{l}\text { When people think that juuls give you lung cancer but } \\
\text { lung cancer takes years to develop }\end{array}$ & $127(13.9)$ \\
\hline Sarcasm & $\begin{array}{l}\text { Juul, everyone, day, February, simultane- } \\
\text { ously, friend, today, people, college, } \\
\text { think }\end{array}$ & $\begin{array}{l}\text { February } 7,2018 \text {. The day everyone who juuls simul- } \\
\text { taneously got lung cancer. }\end{array}$ & $169(18.5)$ \\
\hline Personal experiences & $\begin{array}{l}\text { Friend, cousin, stop, girl, good, sister, } \\
\text { neighbor, immediately, son, sorority }\end{array}$ & $\begin{array}{l}\text { STOP JUULING IMMEDIATELY, My best friends } \\
\text { neighbors girl friend's sorority sister's cousin's step } \\
\text { son got lung cancer from a single hit of juul. Drop } \\
\text { these cancer sticks. }\end{array}$ & $316(34.5)$ \\
\hline E-cigarette risks & $\begin{array}{l}\text { Juul, link, lung, kid, disease, ecigarette, } \\
\text { severe, flavoring, hit, addict }\end{array}$ & $\begin{array}{l}\text { ecigarette Flavorings linked to Severe LUNG disease } \\
\text { https://t.co/2VhStSkI0s \#lungdisease \#lungcancer } \\
\text { \#ecigarettes \#cancer \#ecigaretteflavoring \#severlungdis- } \\
\text { ease \#howbadareecigarettes }\end{array}$ & $145(15.8)$ \\
\hline
\end{tabular}

Unlike themes expressed in e-cigarette tweets, which showed that users were divided over the association of e-cigarettes with lung cancer, those expressed in smoking tweets (Table 3) showed that users were largely unanimous in perceiving the link between smoking and lung cancer. More than half of tweets $(2251 / 3870,58.1 \%)$ were classified under the theme policy discussion, which equated the importance of tobacco control policies with that of gun control policies. Furthermore, more than $20 \%$ of tweets $(843 / 3870)$ focused on the theme smoking risks-tweets promoted smoking cessation by mentioning scientific facts of smoking and its relation to lung cancer. Another major theme was personal experiences, with $20 \%$ of the tweets (776/3870) having stories of how users or their families suffered lung cancer because of smoking.

Table 3. Smoking themes (based on latent Dirichlet allocation) from tweets.

\begin{tabular}{|c|c|c|c|}
\hline Theme & Words & Examples & Tweets $(\mathrm{n}=3870), \mathrm{n}(\%)$ \\
\hline Policy discussion & & & $2251(58.1)$ \\
\hline Tobacco lobbying & $\begin{array}{l}\text { Tobacco, kid, one, lose, prevent, explain, } \\
\text { love, lobbyist, invite, this }\end{array}$ & $\begin{array}{l}\text { This is like inviting tobacco lobbyists to explain to } \\
\text { kids who have lost loved ones to lung cancer how we } \\
\text { can prevent smoking deaths. Lobbyists don't deserve } \\
\text { a seat at this table. }\end{array}$ & $1831(47.3)$ \\
\hline Smoking risks & $\begin{array}{l}\text { Smoke, cancer, smoker, lung, non, die, } \\
\text { people, risk, quit, cigarette }\end{array}$ & $\begin{array}{l}433 \text { Americans die daily from \#lungcancer. The major- } \\
\text { ity of people living with lung cancer r nonsmokers or } \\
\text { have quit smoking. Anyone, smoker or nonsmoker, } \\
\text { can get lung cancer. While smoking greatly increases } \\
\text { the risk of \#lungcancer, NO ONE DESERVES } \\
\text { CANCER. @ theNCI \#LCSM https://t.co/9CtilnJLzm }\end{array}$ & $843(21.8)$ \\
\hline Personal experiences & $\begin{array}{l}\text { Smoke, get, cigarette, people, die, tobac- } \\
\text { co, cause, someone, kill, make }\end{array}$ & $\begin{array}{l}\text { Great! My big brother was smoking for the last fifty } \\
\text { years Lung cancer finally killed him. Small pain under } \\
\text { the arm one sunny morning. Two years later a } 3 \mathrm{~cm} \\
\text { tumor killed him. }\end{array}$ & $776(20.1)$ \\
\hline
\end{tabular}

\section{Spatial Distributions of E-cigarette and Smoking Tweets and Themes}

The geospatial analysis included $96.7 \%$ (885/915) of the e-cigarette tweets and $89.3 \%$ (3455/3870) of the smoking tweets during National Cancer Prevention Month. Overall, discussions of e-cigarettes and smoking in relation to lung cancer occurred mostly in the coastal areas and the eastern part of the country (Figure 2). California, New York, Florida, Texas, and Illinois had the most tweets about e-cigarettes and smoking. We focused our analysis on states that had more than 20 tweets in order to draw meaningful distribution patterns (Figures S1 and S2 in Multimedia Appendix 1). 
Figure 2. The spatial distribution of e-cigarette and smoking tweets mentioning lung cancer during US national cancer prevention month (February 2018).

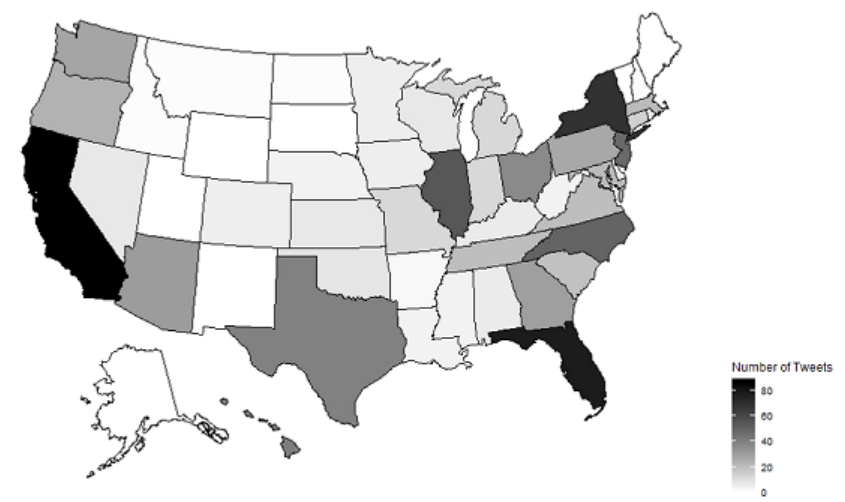

a. E-cigarette

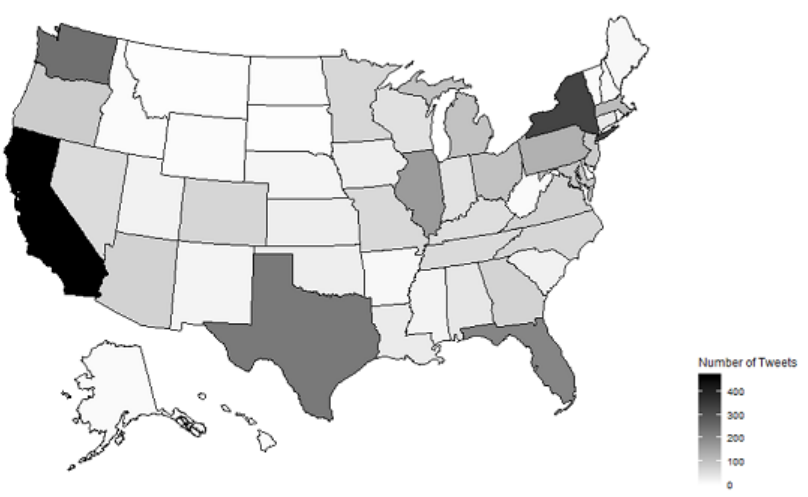

b. Smoking

For e-cigarette tweets, California, Arizona, Pennsylvania, Illinois, and Virginia had more tweets debating e-cigarettes than tweets containing the other two themes. Oregon, Texas, Tennessee, and North Carolina had more tweets asking people to stop vaping based on personal stories. Hawaii and the Washington state had more tweets on scientific evidence showing the link between e-cigarettes and lung diseases.

For smoking tweets, most states predominantly had tweets about policy discussions regarding smoke control and how tobacco control policies were important to reign in tobacco companies, equivalent to how gun control policies would restrict gun lobbyists. Nevada and Kentucky had more tweets about the scientific evidence of smoking risks than those about the other two themes.

\section{Association With State-Level Tobacco Control Policies}

The number of tweets under the theme e-cigarette risks was positively associated with the number of both indoor arena and on campus smoke-free policies (smoke-free indoor: $r_{49}=0.33$, $P=.02$; smoke-free campus: $r_{49}=.32, P=.02$ ). Likewise, the number of tweets under the theme e-cigarette risks was positively associated with the total number of e-cigarette policies, $r_{49}=.32, P=.02$ ). There were no statistically significant associations between the 3 smoking themes and the number of smoking policies in the context of lung cancer $(P>.13)$ (Tables S1 and S2 in Multimedia Appendix 2).

\section{Discussion}

\section{Principal Findings}

We examined the prevailing topics and distributions of discussions in Twitter about e-cigarettes and traditional tobacco consumption during the National Cancer Prevention Month in 2018 within the broader context of lung cancer to offer key insights on how the public perceives health risks of both e-cigarettes and smoking and potentially help public health organizations to be more strategic in their messaging and tobacco control efforts by targeting different tobacco products.

First, the findings of temporal distributions of e-cigarette and smoking tweets suggest that National Cancer Prevention Month promoted both e-cigarette and smoking conversations related

to lung cancer. What we found notable was that National Cancer Prevention Month promoted e-cigarette conversations more than smoking conversations in the context of lung cancer. Without the cancer campaigns, lung cancer discourse on Twitter were rarely about e-cigarettes $(76 / 10,153,0.75 \%)$ and mostly revolved around the harms of smoking $(1824 / 10,153,18.0 \%)$. This is likely for a few reasons. In February 2018, the American Cancer Society [42] first released an official statement that discouraged youths or young adults from using any tobacco products including e-cigarettes. As such, it might have generated additional attention to the harms of e-cigarettes in relation to lung cancer during National Cancer Prevention Month. Second, 2018 National Youth Tobacco Survey data raised concerns about the vaping epidemic by showing an alarming surge in e-cigarette use among youths from 2017 to 2018; there was a $78 \%$ increase in e-cigarette use among high school students and a $48 \%$ increase among middle school students [43]. In addition, the nature of National Cancer Prevention Month itself, as a cancer awareness campaign, did indeed promote public debate and concerns about e-cigarettes on Twitter as demonstrated by our data.

Second, the findings of our thematic analysis suggest that Twitter users were aware of the risks of lung cancer from smoking but were split over the potential health effects of vaping. While some of the Twitter users evaluated the link between e-cigarettes and lung cancer based on personal experiences or anecdotal stories they have heard, others processed e-cigarette information in a more cerebral manner and were convinced of the health risks of e-cigarettes. This split in attitude toward e-cigarettes may be the result of mixed communication messaging from public health organizations. For instance, while the CDC has acknowledged the risks of e-cigarettes, particularly for young people due to the presence of nicotine, the long-term health effects of e-cigarettes have been debated [44]. And the National Academies of Sciences, Engineering, and Medicine [10] released a report concluding that e-cigarette use could not be strictly categorized as harmful or beneficial because it would require more long-term studies on the health effects of vaping.

Another significant finding was that themes of political lobbying and policy making were absent from e-cigarette tweets, but not from those about traditional tobacco consumption, during the 
cancer campaign. When discussing smoking, Twitter users were mindful of the political lobbying by tobacco industries (and equated it to that of gun lobbyists), but this particular theme was missing from e-cigarette tweets. This is crucial, as it suggests that the political lobbying efforts by e-cigarette companies may not be as visible or prominent as those of the traditional tobacco industry. This is a cause for concern. After all, the tobacco industry is very much involved in the e-cigarette industry, as shown by the acquisition of Juul by Altria (formerly known as Philip Morris) for US \$12.8 billion in 2018 [45]. Moreover, in recent years, e-cigarette companies have increased efforts in boosting scientific legitimacy in the context of health effects from consumption of their vaping products. For instance, Juul established the JLI Science lab, to fund scientific research on the effects of vaping products - a move that resembled the tobacco industries' use of research for political lobbying efforts in the 1980s [46]. In terms of policy actions, public debate on the need for tighter regulations over e-cigarettes is critical. Research has shown that supply-side restrictions-such as limiting tobacco retail outlet density - are effective in reducing tobacco consumption [47]. If there are any indications that the current ban on flavored e-cigarettes by the United States and other countries has an effect on the tobacco industry, Altria will revise terms of investments in Juul [48].

Third, this study demonstrated geospatial differences in e-cigarette and smoking discussions on Twitter during National Cancer Prevention Month. In terms of discussing e-cigarette risks, results showed that only 2 states-Hawaii and Washington-had more discussions than those of the others. In the state of Washington, $30 \%$ of 12 th grade students used e-cigarettes [49], compared to the use of other tobacco products such as smokeless tobacco (4\%) or cigars (7\%). In the state of Hawaii, high school teenagers vaped twice as much as the national average [50]. To curb the vaping epidemic, Hawaii was one of the first states to raise the legal age of sales for tobacco from 18 years to 21 years, in an effort to prevent young people from nicotine addiction and the harms of tobacco use [51].

There was a positive correlation between discussion of e-cigarette risks and the number of smoke-free policies at the state level. While the findings cannot be used to make any causal claims, it is worth nothing that there may be a reciprocal relationship between public awareness of e-cigarette risks and the passing of smoke-free policies. In other words, when the public becomes aware of the risks of e-cigarettes, they may encourage local representatives to push for more smoke-free policies. At the same time, the passing of smoke-free policies may further increase awareness of e-cigarette risks in the general public.

Though discussion of tobacco risks and the number of smoke-free policies were not correlated, as discussed, people still mentioned the importance of smoking control policies in their tweets. The data suggest that policy engagement and public awareness and discussion of tobacco risks are symbiotic. When the risk awareness of a tobacco product is low, especially for emerging tobacco products such as e-cigarettes, public policy engagement motivated by the community leaders or public health organizations may heighten risk awareness. Once the public are adequately educated on the health risks of a tobacco product (eg, combustible cigarettes), this risk awareness may, in turn, fuel discussions on the need for stringent tobacco control policies, as well as strategically address tactics of political lobbying and messaging by the tobacco industry. In other words, the findings of our study suggest that public health organizations should focus on both improving risk awareness of tobacco products, as well as engaging and educating the public on the importance of tobacco control policies, because these strategies complement and reinforce one another.

We believe that our findings will be useful to help health communication scholars understand public perception and attitudes toward e-cigarettes and smoking. Future studies should (1) test potential reciprocal relationship between policy engagement and risk awareness of tobacco products; (2) investigate the underlying mechanisms, specifically examine how National Cancer Prevention Month or other cancer awareness months could promote e-cigarette discussions with randomized controlled trials, and identify the best strategies in educating the public about the harms of vaping; and (3) replicate our study by examining how cancer awareness months drive conversations about other cancers (eg, breast cancer, prostate cancer) compared with other noncancer awareness months and how various health policies (eg, health insurance) across different states are associated with cancer discussion.

\section{Limitations}

First, while social media sources, such as Twitter, can be used to gauge public opinion and sentiments toward smoking and e-cigarette, we are mindful that they may not be representative, and as such, there are constraints on the generalizability of the results. For example, our data came from publicly available posts, and thus, we were not able to capture themes and sentiments toward smoking and e-cigarettes in private posts. Also, because not all users reported their locations in their profiles, there may be potential selection biases in the geospatial analysis. In addition, we are cognizant that there potentially could be a spill-over effect because our data were collected from consecutive months in February and March. However, we are confident that this was not a major issue of concern given that the number of e-cigarette tweets in February $(n=1061)$ during National Cancer Prevention Month was much greater than the number of e-cigarette tweets in March $(n=171)$. Finally, we excluded tweets with both sets of keywords that might introduce bias and ran the same analyses; we found that the results did not substantially differ; therefore, we are confident that our results are robust.

\section{Conclusion}

The public is aware of smoking and lung cancer risks, but people were generally divided over the risks of e-cigarettes in relation to lung cancer. Public health organizations should invest in strategic messaging efforts over social media to address any misinformation about e-cigarettes because there is a reciprocal relationship between public awareness and discussion on tobacco products on social media and the implementation of tobacco control policies. 


\section{Acknowledgments}

This project was supported by a research grant from Nanyang Technological University (grant M020060110).

\section{Authors' Contributions}

JL and EL contributed to the design of the study. JL performed the analyses. JL and EL drafted the manuscript. Both authors contributed to revision of the manuscript and approved the final version for submission.

\section{Conflicts of Interest}

None declared.

\section{Multimedia Appendix 1}

The spatial distribution of Twitter themes in relation to lung cancer during US national cancer prevention month (February 2018). [DOCX File, 268 KB-Multimedia Appendix 1]

\section{Multimedia Appendix 2}

Correlation between the tweet number of themes and the number of state-level tobacco policies.

[XLSX File (Microsoft Excel File), 18 KB-Multimedia Appendix 2]

\section{References}

1. Tobacco control. World Health Organization. URL: https://www.who.int/tobacco/control/en/ [accessed 2021-12-13]

2. WHO report on the global tobacco epidemic, 2017: monitoring tobacco use and prevention policies. World Health Organization. URL: https://www.who.int/publications/i/item/9789241512824 [accessed 2021-12-13]

3. Tobacco-related mortality. Centers for Disease Control and Prevention. URL: https://www.cdc.gov/tobacco/data statistics/ fact sheets/health effects/tobacco related mortality/index.htm [accessed 2021-12-13]

4. Current smoking among adults in 2018 (States). Centers for Disease Control and Prevention. URL: https://www.cdc.gov/ tobacco/data statistics/fact sheets/adult data/cig smoking/index.htm\#states [accessed 2021-12-13]

5. Surgeon general's advisory on e-cigarette use among youth. Centers for Disease Control and Prevention. 2018 Dec. URL: https://www.cdc.gov/tobacco/basic information/e-cigarettes/surgeon-general-advisory/index.html [accessed 2021-12-13]

6. Czaplicki L, Kostygina G, Kim Y, Perks SN, Szczypka G, Emery SL, et al. Characterising JUUL-related posts on Instagram. Tob Control 2020 Nov;29(6):612-617. [doi: 10.1136/tobaccocontrol-2018-054824] [Medline: 31266903]

7. Polosa R, Caponnetto P, Morjaria JB, Papale G, Campagna D, Russo C. Effect of an electronic nicotine delivery device (e-Cigarette) on smoking reduction and cessation: a prospective 6-month pilot study. BMC Public Health 2011 Oct 11;11:786 [FREE Full text] [doi: 10.1186/1471-2458-11-786] [Medline: 21989407]

8. Beard E, West R, Michie S, Brown J. Association between electronic cigarette use and changes in quit attempts, success of quit attempts, use of smoking cessation pharmacotherapy, and use of stop smoking services in England: time series analysis of population trends. BMJ 2016 Sep 13;354:i4645 [FREE Full text] [doi: 10.1136/bmj.i4645] [Medline: 27624188]

9. Zhuang Y, Cummins SE, Sun JY, Zhu S. Long-term e-cigarette use and smoking cessation: a longitudinal study with US population. Tob Control 2016 Oct;25(Suppl 1):i90-i95 [FREE Full text] [doi: 10.1136/tobaccocontrol-2016-053096] [Medline: 27697953]

10. Committee on the review of the health effects of electronic cigarettes of electronic nicotine delivery systems. In: Stratton K, Kwan LY, Eaton DL, editors. Public Health Consequences of E-cigarettes. Washington, DC: National Academies Press; 2018.

11. Bold KW, Kong G, Camenga DR, Simon P, Cavallo DA, Morean ME, et al. Trajectories of e-cigarette and conventional cigarette use among youth. Pediatrics 2018 Jan 04;141(1):e20171832 [FREE Full text] [doi: 10.1542/peds.2017-1832] [Medline: 29203523]

12. Barrington-Trimis JL, Berhane K, Unger JB, Cruz TB, Urman R, Chou CP, et al. The e-cigarette social environment, e-cigarette use, and susceptibility to cigarette smoking. J Adolesc Health 2016 Jul;59(1):75-80 [FREE Full text] [doi: 10.1016/j.jadohealth.2016.03.019] [Medline: 27161417]

13. Kalininskiy A, Bach CT, Nacca NE, Ginsberg G, Marraffa J, Navarette KA, et al. E-cigarette, or vaping, product use associated lung injury (EVALI): case series and diagnostic approach. Lancet Respir Med 2019 Dec;7(12):1017-1026. [doi: 10.1016/S2213-2600(19)30415-1] [Medline: 31711871]

14. Lee H, Park S, Weng M, Wang H, Huang WC, Lepor H, et al. E-cigarette smoke damages DNA and reduces repair activity in mouse lung, heart, and bladder as well as in human lung and bladder cells. Proc Natl Acad Sci U S A 2018 Feb 13;115(7):E1560-E1569 [FREE Full text] [doi: 10.1073/pnas.1718185115] [Medline: 29378943]

15. Rowell TR, Tarran R. Will chronic e-cigarette use cause lung disease? Am J Physiol Lung Cell Mol Physiol 2015 Dec 15;309(12):L1398-L1409 [FREE Full text] [doi: 10.1152/ajplung.00272.2015] [Medline: 26408554] 
16. Outbreak of lung injury associated with the use of e-cigarette, or vaping, products. Centers for Disease Control Prevention. URL: https://www.cdc.gov/tobacco/basic information/e-cigarettes/severe-lung-disease.html [accessed 2021-12-13]

17. Greillier L, Cortot AB, Viguier J, Brignoli-Guibaudet L, Lhomel C, Eisinger F, et al. Perception of lung cancer risk: impact of smoking status and nicotine dependence. Curr Oncol Rep 2018 Mar 05;20(Suppl 1):18. [doi: 10.1007/s11912-017-0650-1] [Medline: 29508085]

18. Baeza-Loya S, Viswanath H, Carter A, Molfese DL, Velasquez KM, Baldwin PR, et al. Perceptions about e-cigarette safety may lead to e-smoking during pregnancy. Bull Menninger Clin 2014 Sep;78(3):243-252 [FREE Full text] [doi: 10.1521/bumc.2014.78.3.243] [Medline: 25247743]

19. Pepper JK, Emery SL, Ribisl KM, Rini CM, Brewer NT. How risky is it to use e-cigarettes? smokers' beliefs about their health risks from using novel and traditional tobacco products. J Behav Med 2015 Apr 28;38(2):318-326 [FREE Full text] [doi: 10.1007/s10865-014-9605-2] [Medline: 25348584]

20. Adkison SE, O'Connor RJ, Bansal-Travers M, Hyland A, Borland R, Yong H, et al. Electronic nicotine delivery systems: international tobacco control four-country survey. Am J Prev Med 2013 Mar;44(3):207-215 [FREE Full text] [doi: 10.1016/j.amepre.2012.10.018] [Medline: 23415116]

21. Pepper JK, Brewer NT. Electronic nicotine delivery system (electronic cigarette) awareness, use, reactions and beliefs: a systematic review. Tob Control 2014 Sep;23(5):375-384 [FREE Full text] [doi: 10.1136/tobaccocontrol-2013-051122] [Medline: 24259045]

22. Kwon M, Park E. Perceptions and sentiments about electronic cigarettes on social media platforms: systematic review. JMIR Public Health Surveill 2020 Jan 15;6(1):e13673 [FREE Full text] [doi: 10.2196/13673] [Medline: 31939747]

23. McCausland K, Maycock B, Leaver T, Jancey J. The messages presented in electronic cigarette-related social media promotions and discussion: scoping review. J Med Internet Res 2019 Feb 05;21(2):e11953 [FREE Full text] [doi: 10.2196/11953] [Medline: 30720440]

24. Hua M, Alfi M, Talbot P. Health-related effects reported by electronic cigarette users in online forums. J Med Internet Res 2013 Apr 08;15(4):e59 [FREE Full text] [doi: 10.2196/jmir.2324] [Medline: 23567935]

25. Martinez LS, Hughes S, Walsh-Buhi ER, Tsou M. "Okay, we get it. you vape": an analysis of geocoded content, context, and sentiment regarding e-cigarettes on Twitter. J Health Commun 2018 Jul 06;23(6):550-562. [doi: 10.1080/10810730.2018.1493057] [Medline: 29979920]

26. Unger JB, Escobedo P, Allem J, Soto DW, Chu K, Cruz T. Perceptions of secondhand e-cigarette aerosol among Twitter users. Tob Regul Sci 2016 Apr 01;2(2):146-152. [doi: 10.18001/trs.2.2.5]

27. Chen AT, Zhu S, Conway M. What online communities can tell us about electronic cigarettes and hookah use: a study using text mining and visualization techniques. J Med Internet Res 2015 Sep 29;17(9):e220 [FREE Full text] [doi: 10.2196/jmir.4517] [Medline: 26420469]

28. Ghosh D, Guha R. What are we 'tweeting' about obesity? mapping tweets with topic modeling and geographic information system. Cartogr Geogr Inf Sci 2013 Mar;40(2):90-102 [FREE Full text] [doi: 10.1080/15230406.2013.776210] [Medline: 25126022]

29. National Cancer Prevention Month. American Association for Cancer Research. URL: https://www.aacr.org/ patients-caregivers/awareness-months/national-cancer-prevention-month/ [accessed 2021-12-13]

30. Lung cancer risk factors. American Cancer Society. URL: https://www.cancer.org/cancer/lung-cancer/causes-risks-prevention/ risk-factors.html [accessed 2021-12-13]

31. Thackeray R, Burton SH, Giraud-Carrier C, Rollins S, Draper CR. Using Twitter for breast cancer prevention: an analysis of breast cancer awareness month. BMC Cancer 2013 Oct 29;13:508 [FREE Full text] [doi: 10.1186/1471-2407-13-508] [Medline: 24168075]

32. Vraga EK, Stefanidis A, Lamprianidis G, Croitoru A, Crooks AT, Delamater PL, et al. Cancer and social media: a comparison of traffic about breast cancer, prostate cancer, and other reproductive cancers on Twitter and Instagram. J Health Commun 2018 Jan 09;23(2):181-189. [doi: 10.1080/10810730.2017.1421730] [Medline: 29313761]

33. Diddi P, Lundy LK. Organizational Twitter use: content analysis of Tweets during breast cancer awareness month. J Health Commun 2017 Mar 19;22(3):243-253. [doi: 10.1080/10810730.2016.1266716] [Medline: 28248621]

34. Lee EW, Ho SS, Chow JK, Wu YY, Yang Z. Communication and knowledge as motivators: understanding Singaporean women's perceived risks of breast cancer and intentions to engage in preventive measures. J Risk Res 2013 Aug;16(7):879-902. [doi: 10.1080/13669877.2012.761264]

35. Cole-Lewis H, Pugatch J, Sanders A, Varghese A, Posada S, Yun C, et al. Social listening: a content analysis of e-cigarette discussions on Twitter. J Med Internet Res 2015 Oct 27;17(10):e243 [FREE Full text] [doi: 10.2196/jmir.4969] [Medline: 26508089]

36. Allem J, Ferrara E, Uppu SP, Cruz TB, Unger JB. E-cigarette surveillance with social media data: social bots, emerging topics, and trends. JMIR Public Health Surveill 2017 Dec 20;3(4):e98 [FREE Full text] [doi: 10.2196/publichealth.8641] [Medline: 29263018]

37. Lienemann BA, Unger JB, Cruz TB, Chu K. Methods for coding tobacco-related Twitter data: a systematic review. J Med Internet Res 2017 Mar 31;19(3):e91 [FREE Full text] [doi: 10.2196/jmir.7022] [Medline: 28363883]

38. Blei D, Ng A, Jordan M. Latent dirichlet allocation. J Mach Learn Res 2003;3:993-1022 [FREE Full text] 
39. Grün B, Hornik K. Topicmodels: an R package for fitting topic models. J Stat Soft 2011;40(13):1-30. [doi: 10.18637/jss.v040.i13]

40. Huang L, Ma J, Chen C. Topic detection from microblogs using T-LDA and perplexity. 2017 Presented at: 24th Asia-Pacific Software Engineering Conference Workshops (APSECW); December 4-8; Nanjing, Jiangsu, China p. 71-77. [doi: 10.1109/apsecw.2017.11]

41. Tobacco use - legislation. Centers for Disease Control and Prevention. URL: https://chronicdata.cdc.gov/ browse?category=Legislation [accessed 2021-12-13]

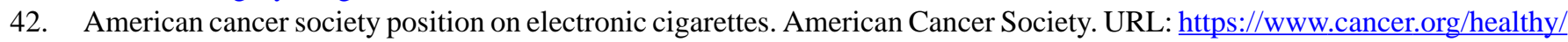
stay-away-from-tobacco/e-cigarettes-vaping/e-cigarette-position-statement.html [accessed 2021-12-13]

43. Cullen KA, Ambrose BK, Gentzke AS, Apelberg BJ, Jamal A, King BA. Use of electronic cigarettes and any tobacco product among middle and high school students - United States, 2011-2018. MMWR Morb Mortal Wkly Rep 2018 Nov 16;67(45):1276-1277 [FREE Full text] [doi: 10.15585/mmwr.mm6745a5] [Medline: 30439875]

44. Talking to youth and young adults to prevent e-cigarette use. Centers for Disease Control and Prevention. URL: https:/ /www.cdc.gov/features/ecigarettes-young-people/index.html [accessed 2021-12-13]

45. Levy DT, Sweanor D, Sanchez-Romero LM, O'Connor R, Goniewicz ML, Borland R. Altria-Juul Labs deal: why did it occur and what does it mean for the US nicotine delivery product market. Tob Control 2020 Dec 04;29(e1):e171-e174 [FREE Full text] [doi: 10.1136/tobaccocontrol-2019-055081] [Medline: 31484802]

46. Tan ASL, Soneji S, Moran MB, Choi K. JUUL Labs' sponsorship and the scientific integrity of vaping research. The Lancet 2019 Aug;394(10196):366-368. [doi: 10.1016/s0140-6736(19)31718-0]

47. Ackerman A, Etow A, Bartel S, Ribisl KM. Reducing the density and number of tobacco retailers: policy solutions and legal issues. Nicotine Tob Res 2017 Feb 28;19(2):133-140 [FREE Full text] [doi: 10.1093/ntr/ntw124] [Medline: 27127232]

48. Feuer W. Altria stock craters after $\$ 4.1$ billion hit from Juul investment, blames growing legal risk. CNBC. URL: https:/ /www.cnbc.com/2020/01/30/altria-is-taking-a-4point1-billion-charge-on-its-investment-in-juul.html [accessed 2021-12-13]

49. Tobacco use in Washington 2019. Truth Initiative. URL: https://truthinitiative.org/research-resources/smoking-region/ tobacco-use-washington-2019 [accessed 2021-12-13]

50. Understanding youth vaping in Hawaii. The Hawaii Department of Health. URL: https://www.healthyhawaii.com/ tobacco-free/vaping/ [accessed 2021-12-13]

51. Extinguishing the tobacco epidemic in Hawaii. Centers for Disease Control and Prevention. URL: https://www.cdc.gov/ tobacco/about/osh/state-fact-sheets/hawaii/index.html [accessed 2021-12-13]

\section{Abbreviations \\ CDC: Centers for Disease Control and Prevention \\ e-cigarette: electronic cigarette}

Edited by R Kukafka; submitted 18.02.21; peer-reviewed by W Chu, C Hudak; comments to author 15.04.21; revised version received
08.06.21; accepted 08.11.21; published 29.12.21
Please cite as:
Lu J, Lee EWJ
Examining Twitter Discourse on Electronic Cigarette and Tobacco Consumption During National Cancer Prevention Month in 2018:
Topic Modeling and Geospatial Analysis
J Med Internet Res 2021;23(12):e28042
URL: $\underline{\text { https://www.jmir.org/2021/12/e28042 }}$
doi: 1 10.2196/28042
PMID:

CJiahui Lu, Edmund W J Lee. Originally published in the Journal of Medical Internet Research (https://www.jmir.org), 29.12.2021. This is an open-access article distributed under the terms of the Creative Commons Attribution License (https://creativecommons.org/licenses/by/4.0/), which permits unrestricted use, distribution, and reproduction in any medium, provided the original work, first published in the Journal of Medical Internet Research, is properly cited. The complete bibliographic information, a link to the original publication on https://www.jmir.org/, as well as this copyright and license information must be included. 